\title{
A Social Cognitive Theory: Perspective of the Sugary Drink Cup Size Policy
}

\author{
Eribeth Penaranda*, Francois Modave and Marco Diaz
}

Department of Family Medicine, PLFSOM, TTUHSC-El Paso. TX, USA

\begin{abstract}
In an attempt to fight the obesity epidemic, an unprecedented policy banning the sale of sugary beverages in containers over 16 ounces in selected public venues was proposed the city of New York. This policy is not without opposition from different sectors including the sugary beverage industry and civil organizations that portray it as a violation of consumers' rights to choose. We explore the likelihood of such policy to be successful in curbing the obesity epidemic from a Social Cognitive Theory perspective.
\end{abstract}

Keywords: Behavioral theory, obesity, policy, social cognitive theory.

\section{INTRODUCTION}

In an attempt to curb the obesity epidemic, New York City (NYC) approved a 16 ounce cup size of sugary drinks for mobile food carts, sports arena, and movie theaters, while larger sizes still being available at grocery and convenience stores. Although this measure was expected to be enacted in March 2013, NY Supreme Court Judge, Milton Tingling ruled that the city health board did not have the authority to impose such a policy. Major Bloomberg has vowed to appeal this decision. We are pondering whether such a law could indeed yield a decrease in obesity.

A sugary drink is defined as any non-alcoholic drink containing water (carbonated or not), typically sweetened and flavored, and containing over 25 calories per 8 ounces. This includes sodas, sport drinks, energy drinks, and presweetened iced teas [1]. They are usually sweetened with sugar, high fructose corn syrup, or sugar substitutes (e.g. diet drinks). However, the policy neither applies to diet drinks nor to dairy-based drinks, and refills in restaurants.

The rationale for a ban on large sugary drinks originates from the fact that America faces a growing obesity epidemic whereby $30 \%$ of its current population is considered obese [2] And roughly 300,000 deaths occur annually in the US as a result of obesity and its link with increased risk of chronic conditions such as diabetes, hypertension, heart disease, and certain cancers [3]. The resulting economic burden reached a staggering $\$ 147$ billion in 2008 [4]. In particular, soda consumption has been linked to an increase in the incidence of obesity, diabetes and cardiovascular disease in adults [5]. For children, regular consumption of sugary beverages has been found to be an independent factor for weight gain [6,7] and a predictor of other poor dietary choices [8].

*Address correspondence to this author at the Department of Family Medicine, PLFSOM, TTUHSC-El Paso. TX, USA; Tel: 915-757-3178;

Ext: 276; E-mail: Eribeth.penaranda@ttuhsc.edu
The New York Times reported that most New Yorkers thought that this initiative was a bad idea [9]. In particular, New York citizens were very concerned about an increased involvement of the Government in people's personal choices and expressed skepticism about the effectiveness of this measure to curb obesity, despite the claim that New Yorkers may save about 2.3 million pound per year if the policy were enacted [1].

\section{COULD SUCH POLICY INDEED HELP REDUCE OBESITY OR SHOULD WE BE SKEPTICAL?}

Behavioral theories that predict health behavior provide an important framework to assess the likelihood of measures like this to achieve the intended effect. Social Cognitive Theory (SCT) [10] relies on the idea that learning is partly based on people's experiences, their social interactions and their observed behaviors. Therefore, it emphasizes the dynamic interaction between people and their environment to change people's behavior. Moreover, SCT has been used effectively to explain how constructs such as self-efficacy and self-regulatory behavior are essential for the adoption of healthier nutritional practices [11]. The aim of this paper is to explain why we believe that the ban on large sugary drinks will be an effective first step towards curbing the obesity epidemic, in the context of SCT.

Behavioral changes may result from targeting the societal practices or from individual themselves, and SCT is designed to explain the interactions that exist between environmental and individual practices. Traditionally, the major constructs of the SCT are categorized as psychological determinants of behavior, environmental determinants of behavior, and observational learning.

The main psychological determinants of the behavior are outcome expectation, self-efficacy, and self-regulatory behavior. Outcome expectations represent the learning process of a situation yielding specific outcomes, and the anticipation that if a similar situation occurs again, the 
outcomes would be similar. Therefore, under SCT, behavior is guided by expectations. It is assumed that a person will favor a positive outcome over a negative one. Self-efficacy is the confidence in one's ability to perform a given behavior, whereas self-regulatory behavior is the ability to engage into a behavior to reach a specific goal. These two concepts are key to the adoption of healthier behaviors in the SCT model [11].

The proposed sugary drink policy does not address the main psychological determinants of the SCT. An additional policy requiring the soft drink industry to add labels on their products, warning consumers of the deleterious effects of excessive sugary drink consumption, akin to the disclosures imposed on the Tobacco industry, could complement this policy effectively. However, as we will see, the targeting of the environmental aspects of the SCT is a first step in the right direction to trigger the necessary changes to lower obesity rates.

Observational learning is defined as the learning process and reinforcement that occur while watching the behavior of others. Seeing others drinking smaller drinks could lead one to reassess what is an appropriate soft drink size, and reinforce his/her own choices. This is particularly true for children in whom a model to follow is the more effective way of learning [12].

Environmental determinants are external and physical factors which influence behavior. For instance, there has been a parallel increase in soda consumption with increased soda container size, from the 7-8 oz. standard in the 1950s, up to $64 \mathrm{oz}$. drinks that can be readily found today [13]. Supply, but not demand, has been the driving force for increased sugary beverage consumption. The 16-ounce-cup on size of sugary beverages introduces a new theoretically less harmful size and has the potential of becoming consumers' preferred choice. Although the main psychological components of SCT are not targeted directly by the sugary drink cup size policy, the environmental factors are, and therefore, we think that the policy has created an environment that is conducive to yield observational learning, and thus to individual behavior changes, e.g. healthier changes. Indeed, container size gives the consumer a suggestion of what is normal, by modifying his/her perception of normality in his/her environment. Research supports that visual cues are used to estimate calories and portion size [14].

The current consumption of sugary beverages is not in adequation with a healthy lifestyle and is major contributor to the obesity epidemics. Obesity not only affects individuals that suffer from it, but also adds an incredible economic burden to the health care system. Although libertarians' views argue that individual freedom should prevail despite the known health risks, from a public health standpoint, societal gains should be what lead this discourse in order to have a healthier society.

Public health policy has proven effective in changing unhealthy behaviors in other instances (e.g. mandatory use of seat belts, banning smoking from public places), therefore a policy that attempts to decrease the amount of sugary beverage consumption is a viable measure to curb obesity, and a policy approving a 16 ounce cup size on sugary beverage could make it easier for the regular consumer to make healthier decisions.

Although the sugary drink cup size policy does not directly target all the constructs of SCT, we believe that its focus on reciprocal determinism and observational learning will positively affect outcome expectations, self-efficacy, and self-regulatory behavior by providing better visual cues for normality (portion control). Additional policies could be added later to strengthen the current policy, and directly target the psychological constructs of the SCT. For instance, warning label policies, combined with educational campaigns, similar to the comprehensive smoking cessation programs, would directly target outcome expectations, and self-efficacy.

In conclusion, SCT provides a framework that demonstrates that the sugary drink cup size policy is likely to be effective in curbing the obesity epidemic, and it does set a precedent by which subsequent policies aimed at decreasing the obesity epidemic in the US could take place.

\section{CONFLICT OF INTEREST}

The authors confirm that this article content has no conflicts of interest.

\section{ACKNOWLEDGEMENTS}

Declared none.

\section{REFERENCES}

[1] Kansagra S. Maximum Size For Sugary Drinks: Proposed Amendment of Article 81; 2012.

[2] Vital signs: state-specific obesity prevalence among adults --United States. MMWR Morb Mortal Wkly Rep 2010; 59(30): 9515.

[3] Haslam DW, James WP. Obesity. Lancet 2005; 366(9492): $1197-$ 209.

[4] Finkelstein EA, Trogdon JG, Cohen JW, Dietz W. Annual medical spending attributable to obesity: payer-and service-specific. Health Aff (Millwood) 2009; 28(5): w822-31.

[5] Malik VS, Popkin BM, Bray GA, Després JP, Hu FB. Sugarsweetened beverages, obesity, type 2 diabetes mellitus, and cardiovascular disease risk. Circulation 2010; 121(11): 1356-64.

[6] Ebbeling CB, Feldman HA, Chomitz VR, et al. A randomized trial of sugar-sweetened beverages and adolescent body weight. N Engl J Med 2012; 367(15): 1407-16.

[7] de Ruyter JC, Olthof MR, Seidell JC, Katan MB. A trial of sugarfree or sugar-sweetened beverages and body weight in children. $\mathrm{N}$ Engl J Med 2012; 367(15): 1397-406.

[8] Fiorito LM, Marini M, Mitchell DC, Smiciklas-Wright H, Birch LL. Girls' early sweetened carbonated beverage intake predicts different patterns of beverage and nutrient intake across childhood and adolescence. J Am Diet Assoc 2010; 110(4): 543-50.

[9] Times NY. 60\% in City Oppose Bloomeberg's Soda Ban, Poll Finds. 08/23/2012; http://www.nytimes.com/2012/08/23/nyregion/most-new-yorkers-oppose-bloombergs-soda-ban.html. Accessed 11/15/2012.

[10] Glanz K, Rimer BK, Viswanath K. Health Behavior and Health Education. Theory, Research and Practice. United States of America: Jossey-Bass A Wiley Imprint. 989 Market Street. San Francisco, CA 94103-1741; 2008.

[11] Anderson ES, Winett RA, Wojcik JR. Self-regulation, self-efficacy, outcome expectations, and social support: social cognitive theory and nutrition behavior. Ann Behav Med 2007; 34(3): 304-12. 
[12] Bandura A. Psychological modeling: Conflicting theories. Vol Social learning and personality; Chicago: Aldine-Atherton, 1971.

[13] Nielsen SJ, Popkin BM. Changes in beverage intake between 1977 and 2001. Am J Prev Med 2004; 27(3): 205-10.
[14] Wansink B, Painter JE, North J. Bottomless bowls: why visual cues of portion size may influence intake. Obes Res 2005; 13(1): 93100 .

Received: October 29, 2013

Revised: January 15, 2014

Accepted: January 20, 2014

(c) Penaranda et al.; Licensee Bentham Open.

This is an open access article licensed under the terms of the Creative Commons Attribution Non-Commercial License (http://creativecommons.org/licenses/by-nc/3.0/) which permits unrestricted, non-commercial use, distribution and reproduction in any medium, provided the work is properly cited. 